\title{
Percepção de professores-pesquisadores sobre questões éticas em pesquisas on-line
}

\author{
Luiz Wilson Machado da Costa e Silva Neto $^{1}$, Deise Juliana Francisco ${ }^{1}$
}

1. Universidade Federal de Alagoas, Maceió/AL, Brasil.

\section{Resumo}

O artigo investiga a percepção de professores-pesquisadores em relação à ética em pesquisa on-line. Trata-se de estudo qualitativo que entrevistou profissionais vinculados a programas de pós-graduação em educação de universidades brasileiras que atuam com tecnologias digitais da informação e comunicação. Os dados foram organizados em mapa dialógico, cuja análise permitiu identificar alguns sentidos atribuídos à ética em pesquisa. Os entrevistados demonstraram reconhecer a importância da ética em pesquisa on-line e compartilharam opiniões, preocupações e críticas que permitiram (des)construir discursos a fim de defender uma prática científica direcionada à proteção dos participantes de pesquisas. Palavras-chave: Ética em pesquisa. Relações pesquisador-sujeito. Pesquisa qualitativa.

\section{Resumen}

\section{Percepción de profesores-investigadores sobre cuestiones éticas en investigaciones en línea}

El artículo investiga la percepción de profesores-investigadores acerca de la ética en la investigación en línea. Se trata de un estudio cualitativo, que entrevistó a profesionales vinculados a programas de educación de posgrado en universidades brasileñas y que trabajan con tecnologías digitales de la información y la comunicación. Se organizaron los datos en un mapa dialógico, cuyo análisis permitió identificar algunos significados atribuidos a la ética de la investigación. Los encuestados demostraron reconocer la importancia de la ética en la investigación en línea y compartieron opiniones, preocupaciones y críticas que permitieron (des)construir discursos para defender una práctica científica orientada a proteger los participantes de investigaciones.

Palabras clave: Ética en investigación. Relaciones investigador-sujeto. Investigación cualitativa.

\begin{abstract}
Perception of professor-researchers on ethical issues in online research

This article analyzes the perception of professors on online research ethics. This qualitative study interviewed professionals linked to graduate programs in Brazilian universities, who work with digital information and communication technologies. Data were organized in a dialogic map, whose analysis allowed identifying meanings attributed to research ethics. Respondents recognized the importance of ethics in online research and shared opinions, concerns, and criticisms that allowed (de)constructing discourses to defend a scientific practice aimed at protecting research participants.
\end{abstract}

Keywords: Ethics, research. Researcher-subject relations. Qualitative research. 
Vivemos na sociedade da informação e do conhecimento, na qual a revolução digital tem papel importante. Por meio dos avanços das tecnologias digitais de informação e comunicação (TDIC), os sujeitos têm acesso a grande quantidade de dados, dos mais variados campos do conhecimento. Pierre Lévy ${ }^{1}$ afirma que é imprescindível aprender a conviver com isso, pois estamos vivendo um "dilúvio de informações", em que é preciso identificar o essencial, pois não podemos absorver tudo o que está disponível. Assim, cada indivíduo e grupamento deve organizar, selecionar e hierarquizar os dados a fim de dar-lhes sentido.

As TDIC estão cada vez mais presentes no âmbito da produção do conhecimento, e cresce o número de publicações sobre pesquisa on-line ${ }^{2}$. A partir de diálogo com professores-pesquisadores inseridos nesse campo, este estudo pretende compreender questões éticas envolvidas na produção do conhecimento on-line. O fenômeno é aqui abordado sob a perspectiva do construcionismo, que concebe a realidade como socialmente construída, destacando a interação do sujeito com o contexto de que faz parte na produção de sentido da vida cotidiana.

De acordo com Spink e Frezza, a linguagem é, nessa visão, um produto social: o construcionismo reconhece a centralidade da linguagem nos processos de objetivação que constituem a base da sociedade de humanos ${ }^{3}$. Entendendo a linguagem dessa forma, o construcionismo enfoca práticas discursivas. Tal perspectiva, em especial na vertente de Jonathan Potter e lan Parker, segundo Spink e Frezza, procura problematizar o contexto discursivo, sem perder de vista a interação ${ }^{4}$, o que implica ações, seleções, escolhas, linguagens, contextos, enfim, uma variedade de produções sociais das quais [as práticas discursivas] são expressão ${ }^{5}$. Nesse sentido, o processo investigativo amparado na perspectiva das práticas discursivas desloca os interesses e as explicações para o modo como as pessoas falam e que repertórios usam ao descrever a realidade em que vivem ${ }^{6}$.

Este trabalho mobiliza ainda bibliografia que aborda a forma como os argumentos do construcionismo são elaborados e de que maneira os repertórios colaboram para a coprodução de práticas nos diferentes cenários sociais relacionados com ética em pesquisa on-line. Em revisão de literatura, Fare, Machado e Carvalho ${ }^{7}$ encontraram número considerável de trabalhos que problematizam diferentes aspectos da pesquisa educacional de modo geral ou a partir de certos recortes (educação especial, física, matemática, musical, linguística), ou abordavam temas como fracasso escolar e formação de professores. Havia, porém, poucas publicações específicas sobre ética, e menos ainda sobre regulações e diretrizes.

Fare ${ }^{8}$ aponta duas linhas na formação em ética: uma voltada à perspectiva operacional das diretrizes éticas e outra aos dilemas que emergem em contextos de pesquisa. Como alternativa ao primeiro modelo, a autora propõe abordagem pautada na "construção do sentido ético" da própria pesquisa, que envolveria processo de metacognição de questões éticas que abrange a reflexão sobre o processo decisório e aspectos subjacentes (circunstâncias, ajuda externa, juízos pessoais de valor, emoções, motivações do pesquisador etc.).

Alia-se ainda esta discussão às determinações do Conselho Nacional de Saúde (CNS), em especial a Resolução CNS 466/2012 ${ }^{9}$ e a Resolução CNS $510 / 2016^{10}$, que estabelecem diretrizes para a prática ética de pesquisa, expondo termos, procedimentos e reflexões pertinentes à área da educação.

Com base nessa bibliografia, o estudo se propõe a investigar questões de ética em pesquisa com seres humanos no âmbito da internet, visando compreender os desafios específicos desse contexto. A análise partiu da seguinte pergunta: de que maneira professores-pesquisadores pensam a ética na realização de pesquisas em ambientes on-line?

\section{Método}

Trata-se de estudo qualitativo realizado com professores-pesquisadores que atuam com as TDIC na área da educação. Foram realizadas pesquisas na Plataforma Lattes e em sites dos programas de pós-graduação a fim de obter o contato dos docentes, e em seguida foram enviados convites por e-mail e/ou pela rede social Facebook. Ao fim desse processo, sete professores aceitaram participar e agendaram entrevista.

De acordo com os critérios de inclusão, foram selecionados docentes-pesquisadores que participassem de grupos de pesquisa em TDIC para formação presencial e on-line de professores e/ou que fossem vinculados a programas de pós-graduação na área e que tenham contribuído 
para a produção de conhecimento sobre o tema. Participaram da pesquisa professores da Universidade Federal de Alagoas, Universidade Federal de Sergipe, Universidade Federal de Pernambuco, Universidade Federal do Ceará, Universidade Federal da Bahia, Universidade do Estado do Rio de Janeiro e Universidade Estadual de Campinas.

As entrevistas se basearam em roteiro previamente estabelecido, mas flexível. $O$ instrumento contava com dois blocos de informação: o primeiro incluía dados de identificação do participante (tempo de atuação como professor-pesquisador, tempo de atuação com TDIC na educação, formação em ética em pesquisa, meios de coleta de dados utilizados); o segundo abordava questões sobre ética em pesquisa (normatização, cuidados éticos, consentimento livre e esclarecido em espaços on-line, regras éticas para a comunicação eletrônica etc.).

Os professores vinculados à Universidade Federal de Alagoas foram entrevistados presencialmente, devido à proximidade geográfica; as demais entrevistas foram realizadas remotamente, via Skype ou Google Hangouts. O tempo médio de cada encontro foi de 40 minutos. $O$ termo de consentimento livre e esclarecido (TCLE) foi lido e aceito antes das entrevistas. Nos encontros on-line, o documento assinado foi enviado por e-mail.

Em conformidade com a Resolução CNS 466/2012 ${ }^{\circ}$ e a Resolução CNS 510/2016 ${ }^{10}$, buscou-se, em todas as etapas do trabalho, proteger os participantes, assegurando-se sua dignidade, liberdade, autonomia e anonimato. Os procedimentos não ofereceram riscos maiores que os encontrados na rotina dos professores-pesquisadores, que não foram identificados, permaneceram em anonimato e foram informados de que podiam retirar seu consentimento a qualquer momento, sem qualquer prejuízo. A pesquisa não trouxe gastos financeiros para os participantes nem houve necessidade de ressarcimento.

O objetivo do estudo é servir de fonte de informação para as decisões de membros de órgãos e comitês que tratam de ética na pesquisa com seres humanos. Buscou-se ainda favorecer a reflexão sobre questões que provocam dúvidas entre professores-pesquisadores da educação ou que estão sendo negligenciadas na produção do conhecimento científico.

\section{Análise dos dados}

A análise de dados envolveu três passos: transcrição sequencial, transcrição integral e construção de mapa dialógico, utilizado como ferramenta para evidenciar significados produzidos durante a pesquisa. Na transcrição sequencial buscou-se identificar quem fala (entrevistado) e sobre o que fala (assunto), de modo a observar os temas que emergiram. Dentre esses temas estão: ética em pesquisa, especificidades da ética da pesquisa on-line, críticas, proteção, normatização, desconhecimento, Plataforma Brasil e estratégias de enfrentamento.

A transcrição integral das falas foi realizada a fim de preservar os discursos originais produzidos na pesquisa. As linhas transcritas foram enumeradas para localizar recortes de fala dos entrevistados no mapa dialógico. Visando garantir o anonimato, o nome dos participantes foi substituído pela letra "E", de "entrevistado", seguida de número: E1, E2, E3, E4, E5, E6 e E7.

O mapa dialógico foi construído com base nas transcrições sequencial e integral. De acordo com Pereira, Schmitt e Dias, tal ferramenta é composta por colunas que podem ser divididas de acordo com os temas que, em geral, refletem a sistematização dos conteúdos obtidos ${ }^{11}$. Foram criadas colunas verticais com temas identificados na transcrição sequencial da fala dos participantes, posteriormente preenchidas com a transcrição integral das falas. O mapa foi construído e organizado em dois eixos: considerações sobre o conceito de ética em pesquisa e proteção aos participantes; e especificidades éticas da pesquisa on-line.

\section{Ética em pesquisas on-line}

Os significados produzidos nas entrevistas trouxeram tanto aspectos comuns quanto diversos sobre a ética no trabalho dos professores-pesquisadores. Isso não surpreende, uma vez que as falas estão baseadas em experiências singulares, construídas e vividas durante a trajetória particular de cada entrevistado. Assim, singularidades influenciaram as entrevistas, ainda que tenham sido encontrados elementos comuns, como a ausência de formação em ética em pesquisa, relatada por todos os entrevistados apesar da diversidade de áreas de formação (E1, biologia; E2, psicologia; E3 e E5, pedagogia; E4, matemática; E6, sociologia; E7, filosofia). 


\section{Considerações sobre o conceito de ética em pesquisa}

Por ser produto das relações sociais, a ética não é conceito estável. Assim, tanto a definição do que é ética em pesquisa como sua regulamentação estão arraigadas em contextos históricos e sociais. Nesse sentido, os professores compreendem que sua atividade envolve um outro na posição de participante da pesquisa, alguém que necessita de cuidados, tal como aponta a Resolução CNS 510/2016 ${ }^{10}$. Os entrevistados chamam atenção para a importância da ética na produção do conhecimento:

"Ela é fundamental, porque nós temos sujeitos envolvidos com visões diferentes, com perspectivas políticas e culturais diferentes; portanto, esse cuidado nós devemos ter. (...) Independente de como esse sujeito vai se manifestar nos instrumentos que eu vou usar para coletar dados, eu vou ter que ter cuidados éticos" (E1).

"Eu aprendi desde cedo que a ética na profissão, qualquer que seja a profissão, é muito importante. (...) Então é dentro dessa visão que a gente tem que trabalhar com a pesquisa cientifica e é dessa forma que eu procuro trabalhar" (E2).

"Eu acho fundamental, sabe por quê? Cada dia mais a gente precisa ter cuidado com a forma como a gente trata o outro da pesquisa (...) Sempre, quando estou em banca, questiono isso. Acho fundamental que seja esclarecido para os sujeitos qual o objeto da pesquisa, qual a intenção dele, qual a implicação disso para o sujeito. Acho fundamental a existência de termos de consentimento livre e esclarecido, o TCLE" (E3).

"A ética em pesquisa não só é necessária, como o debate [sobre ela] tem que ser intensificado" (E4).

"Eu acho essencial, eu defendo isso (...) Eu tenho alguns problemas - problemas, não, divergências com alguns colegas que acham desnecessário" (E5).

Na fala "esse cuidado nós devemos ter", em referência à proteção do participante da pesquisa, E1 aborda o cuidado para além da esfera biomédica. No campo das ciências humanas e sociais, o cuidado pode ser entendido como a forma ética com que os pesquisadores se relacionam com o outro, o participante da pesquisa. Isso implica considerar esse outro como colaborador, respeitando suas contradições e singularidades. Como propõe Schmidt, a colaboração e/ou interlocução como atmosfera de muitos exemplos de investigações participativas supõe, do pesquisador, uma constante atividade autorreflexiva, bem como a elaboração da problemática do outro, não mais como "objeto", mas como parceiro intelectual no exame do fenômeno que se quer conhecer ${ }^{12}$.

Ao falar da ética na profissão, E2 traz enfoque ético tradicional, característico dos códigos e juramentos. No entanto, no contexto da ética em pesquisa, como apontam Guilhem e Diniz, apenas indicar "faça isso, não faça aquilo" não seria suficiente para assegurar ao sujeito um sistema moral unificado que orientasse a ação ${ }^{13}$. Tal perspectiva representa grande limitação no trato dos conflitos morais relacionados ao ser humano, ao seu bem-estar e ao mundo em que vive.

Nesse sentido, quando se adotam modelos éticos universais, tal como se vê na vertente principialista, negligencia-se a dimensão intersubjetiva dos participantes da pesquisa, assim como suas narrativas particulares dentro de contextos sociais específicos. Por conta dessas incompatibilidades causadas por diferenças culturais, o multiculturalismo fortalece o movimento crítico ao principialismo, contrapondo-se às propostas universalizantes da ética filosófica. Essa noção destaca compromisso com as diferentes visões dos sujeitos envolvidos no estudo, o que remete a Engelhardt ${ }^{14}$, que defende pluralidade moral, implicando uma ética que dê conta de discordâncias e diferenças morais em favor do convívio social responsável e pacífico.

Verifica-se, na fala de E3, que seu argumento parte de perspectiva que relaciona ética e direito, destacando direitos individuais que precisam ser garantidos, em especial os relativos a privacidade, confidencialidade e sigilo. Nesse sentido, destaca-se a relevância do TCLE enquanto documento que demonstra que o assentimento em participar da pesquisa é autônomo. As questões presentes na fala de E3 remetem ao dilema da produção do conhecimento, que cobra um preço das chamadas "liberdades individuais" do moderno sistema de proteção aos direitos humanos. Nesse contexto, como afirma Dallari, às normas éticas que aconselham o respeito à intimidade, ao sigilo e à confidencialidade se junta, nos Estados contemporâneos, a exigência jurídica de tal respeito, caracterizado como um direito 
individual ${ }^{15}$. Tal dilema é sem dúvida grande desafio, uma vez que é preciso equilibrar o interesse social e a proteção da intimidade do participante.

Já a fala de E4 se concentrou na necessidade de disseminar o ensino de bioética a fim de que haja maior compreensão sobre o tema. A entrevistada mostrou preocupação em orientar os alunos da graduação quanto a cuidados éticos, desde o trabalho de conclusão de curso. Sob essa perspectiva, é preciso incentivar os alunos a pensar sobre suas ações em situação de pesquisa e sobre quais são suas consequências para os participantes e a comunidade em geral. Assim, é possível conciliar desde cedo a atividade de pesquisa com o respeito à dignidade humana. Na prática, no entanto, percebe-se carência de espaços para reflexão entre os próprios professores-pesquisadores ${ }^{8}$.

Schmidt ${ }^{16}$ defende a ética como modo de habitar o mundo da produção do conhecimento. Segundo essa perspectiva, a pesquisa contempla, por um lado, a atualização de atitudes e valores quanto à direção e à serventia do conhecimento e, por outro, a interrogação sobre as dimensões políticas e ideológicas do saber produzido no diálogo com um outro. Por dimensão política compreendem-se as relações de poder (dominação ou emancipação) nas práticas de pesquisa, incluindo a geografia dos lugares de escuta, fala e decisão na condução de todas as fases da investigação. Por dimensão ideológica entende-se a produção de efeitos de reconhecimento, desconhecimento, estranhamento e conhecimento no plano das representações do outro ${ }^{17}$.

No trabalho de campo, por exemplo, a relação do pesquisador com os participantes é fundamental. Assim, ainda segundo Schmidt, a forma de pesquisar traduz, ao mesmo tempo, o método e sua ética ${ }^{18}$. Diante disso, cabe ao pesquisador visualizar, para cada desenho de pesquisa, de que maneira método e ética se implicam, desde as fases iniciais do estudo até seu término. $\mathrm{O}$ objetivo é desconstruir práticas naturalizadas a fim de proteger aqueles que interagem e dialogam com o pesquisador durante a investigação.

\section{Proteção}

No contexto da ética em pesquisa, o respeito pela dignidade humana se direciona em especial à proteção dos participantes, embora também vise assegurar os direitos e deveres da comunidade científica. De maneira geral, no Brasil, as normas éticas, cuja observância é de responsabilidade dos Comitês de Ética em Pesquisa, preveem que pesquisadores, ao desenhar e executar determinado projeto, precisam atender a determinadas diretrizes. O respeito à intimidade, com medidas de proteção da confidencialidade e garantia do sigilo, é uma das principais normas abordadas.

Em algumas falas, como a de E2, os professores-pesquisadores enfatizam o cuidado com o outro, participante da pesquisa: "Ter o cuidado e preservar as pessoas, os grupos, é um cuidado que todos nós devemos ter, até para não identificar [os participantes], porque nós não estamos interessados em expor as pessoas" (E2). Outro entrevistado, porém, desloca as preocupações éticas para si, na posição de pesquisador: "Vejo a ética em pesquisa como algo muito importante, porque são garantias que o pesquisador tem de no futuro não responder algum tipo de procedimento jurídico-administrativo por ter usado fontes sem as devidas autorizações" (E1).

$\mathrm{Na}$ fala de E1, a importância da ética se situa apenas na salvaguarda do pesquisador; em contrapartida, E2 ressalta a proteção da integridade do participante da pesquisa, o que aponta para a compreensão de que não pode haver descaso no cuidado com o participante e com o rigor metodológico ${ }^{10}$. Sentidos divergentes, conforme mostram as falas, permitem fazer algumas interrogações: a serviço de quem ou do que se produz conhecimento? O que se deseja quando se produz? Quais são as implicações das pesquisas para a vida dos interlocutores, colaboradores e participantes? Essas questões promovem autorreflexão sobre práticas de trabalho, para além do comportamento de obediência às normas e aos procedimentos avaliados por Comitê de Ética em Pesquisa.

Percebe-se, na fala dos professores, a tensão que representa talvez o maior desafio da ética em pesquisa: equilibrar a preservação dos direitos individuais com o desenvolvimento do conhecimento científico e tecnológico. Para Dallari, esse equilíbrio apenas será alcançado quando todos tiverem consciência de que a percepção dos riscos e sua origem são sociais ${ }^{19}$. Assim, entendendo a ética como produto de convenções sociais historicamente construídas, percebe-se que $\mathrm{o}$ argumento de E2 contempla o relacionamento com o participante da pesquisa a partir da igualdade (todos 
são cidadãos), incluindo respeito à liberdade e cooperação.

\section{Especificidades éticas de pesquisas on-line}

A internet e os espaços virtuais, arquitetados em condição dinâmica, forçam os pesquisadores a trabalhar de novas maneiras, a estudar a sociedade de modos diferentes e a repensar seus instrumentos de modo a se certificar que são apropriados para as tarefas a que são aplicados ${ }^{16}$. Nesse sentido, na tentativa de aprofundar os questionamentos levantados - sem, obviamente, pretender respondê-los ou esgotá-los -, destacam-se aspectos relacionados à especificidade da ética em pesquisa on-line:

"As questões da ética em pesquisa sempre foram objeto de estudo, de discussão, de orientação, mas hoje, por conta do uso das tecnologias, tem-se uma facilidade maior de coletar dados, como também de se ter acesso a diversos textos, de diferentes autores, em diferentes momentos. Isso implica aos envolvidos ter consciência da responsabilidade ética" (E4).

Da fala, depreende-se que a infração ética é concebida como uso socialmente irresponsável do que se produz em situação de pesquisa com auxílio das TDIC. Porém, o desafio está na falta de consciência completa das questões em jogo, muito menos de consenso sobre as melhores maneiras de se proceder. A questão da identificação do participante, por exemplo, é ponto que merece destaque, por ser difícil verificar se as características de si definidas nos espaços on-line correspondem à realidade. Dessa forma, questiona-se: como se pode ter certeza da idade ou da vulnerabilidade do participante? Este ponto é visto como um dos obstáculos para a avaliação ética, como se observa na seguinte fala:

"Um grande problema decorrente do uso da tecnologia é a identidade. Eu não sei até que ponto o sujeito que responde o instrumento de pesquisa é ele próprio. Em alguns casos eu não sei se aquela pessoa que está lá, se diz ser homem, [mas] ela é mulher, se ela diz ter 30 ou pode ter 15. Eu, como pesquisador, não tenho garantia de que esse sujeito é ele mesmo, então isso é algo bastante complicado" (E1).

Moore e Kearsley destacam que nos ambientes virtuais de aprendizagem (AVA) ainda não existe um meio de verificar a identidade do aluno, embora o uso de câmeras em computadores de mesa (as webcams) ofereça efetivamente a possibilidade de realmente ver o candidato para confirmar sua identidade ${ }^{20}$. Na busca de soluções para essa questão, E3 aponta a importância de confrontar informações:

"Eu tenho que ter outros dados, eu tenho quer fazer a triangulação pra ver se efetivamente aquela leitura que eu estou fazendo daqueles dados procede, né? Então eu penso, na minha opinião, que a gente não deve usar apenas um instrumento de investigação. Mesmo que seja uma análise de conteúdo, eu tenho que identificar outros instrumentos que possam fortalecer as informações que eu identifiquei no conteúdo que eu analisei do fórum, por exemplo" (E3).

Outra fala alerta para a importância de evitar apriorismos: "do ponto de vista ético eu não posso partir do pressuposto de que o outro é desonesto. Ele pode ser desonesto, porque no universo on-line eu posso não ser eu, mas a pesquisa precisa ser feita, né" (E7). Esse entrevistado ainda destacou a importância de elaborar bem as perguntas aos participantes, propondo que centrar esforços em questões propositivas seria outra estratégia de enfrentamento.

Mas, afinal, será que essa tensão acerca da identidade do participante é justificada? De acordo com Bauman ${ }^{21}$, as identidades do indivíduo pós-moderno são fluidas e não se enquadram em forma permanente. Há construção contínua de novas identidades, não sendo possível estabelecer um tipo de identidade acabada e verdadeira. No ciberespaço, com as TDIC, indivíduos estabelecem novas formas de interação social que possibilitam (re)criar identidades para desenvolver relações virtuais. Para Pierre Lévy ${ }^{1}$, essa identidade virtual é desterritorializada, dissociada do sentido de tempo e espaço. Por isso mesmo pode ser simultânea, ou seja, um mesmo indivíduo pode utilizar diversas identidades sem que isso represente conflito. Parece aqui, portanto, que o cuidado ético desse indivíduo que colabora com a pesquisa não suporta 
tal verificação, uma vez que o pesquisador corre o risco de reduzir a participação a campo rígido e concreto, incompatível com a mobilidade virtual.

Também a garantia do anonimato do participante no âmbito das pesquisas em AVA é motivo de preocupação: "Se nós estivermos fazendo uma pesquisa no fórum, a não identificação daquele indivíduo é importante porque o que interessa são os conteúdos que estou avaliando ali e não o indivíduo. Então preservar o indivíduo em toda a sua integridade, seja ela moral ou física, a gente tem que fazer sempre" (E2).

Outro ponto que surge nas falas dos participantes refere-se à autorização do uso de dados armazenados nos AVA, como exemplificado na fala a seguir: "Você vai trabalhar com curso on-line que já aconteceu, você vai trabalhar com documentos desse curso, então não necessariamente você vai coletar direto com os alunos ou ex-alunos desse curso, porque o curso já terminou. Você até pode complementar as informações, mas o foco maior de coleta podem ser os documentos, as interações, produções dos alunos desse ambiente virtual, mas mesmo nessas situações você tem que ter autorização dessas pessoas para trabalhar com esses dados" (E4).

Essa questão converge com outra observada em uma das falas, que trata da necessidade de consentimento dos participantes para usar imagens, fotos e vídeos coletados: "O uso de imagens, na forma de vídeo ou na forma de foto, precisa ter autorização dos envolvidos. Geralmente, essa autorização está dentro do TCLE. O problema é que mesmo assim algumas pessoas se negam a disponibilizar a imagem, então isso prejudica muito as pesquisas, principalmente quando a gente usa o recurso da observação e quer comprovar essa observação usando algum tipo de imagem. Com o vídeo a gente está tendo dificuldade. Embora a gente esclareça, as pessoas se negam, achando que vai ser descontextualizada a imagem delas. Isso é um desserviço à pesquisa, no meu entendimento" (E1).

Pode-se, contudo, partir do pressuposto de que os participantes da pesquisa deveriam automaticamente consentir com o uso de sua imagem? A resposta talvez seja bem mais complicada do que parece, requerendo aprofundamento antes que a recusa seja considerada desserviço à pesquisa. A Lei $12.965 / 2014^{22}$, conhecida como Marco Civil da Internet, protege dados pessoais e a privacidade dos usuários, o que exige cuidado ainda maior por parte do pesquisador.

Os professores-pesquisadores apontam dúvidas e inquietações sobre ainda outros aspectos: "Outra questão ética importante é o texto que se escreve no mundo virtual, [os textos] que são escritos nos fóruns, que se escrevem nos blogs, todo tipo de material que se publica na internet que a gente pode usar sem o consentimento, ou se a gente vai ter que fazer consentimento para cada um dos participantes. Por exemplo, numa turma de 100 alunos no AVA, eu vou precisar que eles me autorizem a usar os dados ou o fato de já estarem na disciplina já me concede o direito de uso?" (E1).

De acordo com Bakardjieva e Feenberg ${ }^{23}$, quando os dados on-line começaram a ser utilizados, os pesquisadores tratavam todo o conteúdo encontrado na rede como aberto para uso; porém, com o passar dos anos, essa prática foi obstada por um olhar ético. Para Kozinets ${ }^{24}$, esse tipo de prática revelou aos pesquisadores a necessidade do cuidado ao considerar preocupações éticas de privacidade, apropriação e consentimento.

Nessa perspectiva, é preciso pensar na hipótese de que membros de comunidades e culturas on-line podem não atentar para o fato de que seus textos podem ser lidos e utilizados por outras pessoas. Esses indivíduos, portanto, podem reagir com raiva ou frustação ao uso de suas comunicações em publicações científicas.

Outra questão diz respeito à afirmação de E5 quanto à dificuldade de obter respostas a questionários on-line: "Na pesquisa on-line, o que eu sinto é que as pessoas não respondem. Eu acho que foi a professora A., ela fez uma pesquisa on-line com os tutores, ela queria chorar porque não vinha resposta, ela suplicava, ela ajoelhava. O que é que eu sinto: nós, brasileiros, não temos tradição de responder a nenhum tipo de questionário" (E5).

O trecho apresenta outra personagem: a professora A, cuja voz emerge de seu posicionamento de pesquisadora insatisfeita com a utilização desses questionários, a qual pode ser representativa da opinião de pessoas que fazem parte do seu campo de trabalho. Entretanto, na contramão de seu argumento, pode-se chamar atenção para o fato de que os questionários on-line são cada vez mais populares em diversas áreas, tais como no marketing (pesquisa de mercado) e nas ciências 
sociais e humanas. De acordo com Freitas e colaboradores ${ }^{25}$, dois aspectos devem ser levados em conta pelo pesquisador para aumentar a taxa de retorno rápido e satisfatório: a motivação dos participantes e sua familiaridade com a internet.

Em consonância com a busca de ressignificações, rupturas e produção de novos sentidos, um dos entrevistados afirma que "a gente ainda parte de metodologias que são adequadas e usadas nos ambientes presenciais, e nós precisamos relativizar, pensar, porque nenhuma das duas resoluções pensa essa questão desse tipo de pesquisa no ambiente on-line. Então, a minha questão é: basicamente, a gente ainda não sabe como fazer, apesar de ter mais de 20 anos trabalhando com tecnologias digitais e apesar de a internet já existir há bastante tempo. Já tem várias pesquisas nesses ambientes, mas o referencial ainda está sendo construído" (E3). Embora o desenvolvimento do referencial teórico sobre TDIC em pesquisas se encontre ainda em estágio inicial, como indicado na fala de E3, é preciso incentivar cada vez mais o diálogo, com o fim de estabelecer diretrizes que norteiem práticas éticas nesse campo.

$\mathrm{Na}$ tentativa de produzir novos sentidos para essa discussão, indagou-se a um dos participantes se ele achava possível, no âmbito das pesquisas on-line, criar regras éticas específicas para cada recurso tecnológico. O entrevistado disse acreditar que isso seria inviável, visto que as regras não conseguiriam acompanhar a velocidade dos avanços tecnológicos: "Olhe, quando você está falando nessas regras você está falando em informatização, em regulamentação. Se você fizer isso pra cada instrumento, [para cada] recurso tecnológico, essas normas estarão continuamente desatualizando. Agora, você tem que fazer algo de uma forma mais genérica, que sirva para diferentes recursos, interfaces e tecnologias. (...) Você não pode pôr [tudo] no mesmo pacote, você tem que pensar nas especificidades quando você fala de AVA, blog, Facebook e demais redes sociais" (E4).

Percebe-se, então, a necessidade de ampliar o debate no campo das pesquisas on-line em busca de soluções e posicionamentos gerais em relação a recursos, objetos, locais ou instrumentos de pesquisa. Ainda sobre a possibilidade de regras éticas específicas para cada recurso, E7 enfatiza: "Eu penso que é preciso informar ao pesquisador o que tem e o que já existe. Eu parto primeiro desse princípio: por que eu vou criar algo novo se o pesquisador não conhece nem o que já existe? (...) Penso que o pesquisador, muito mais do que o usuário, ele não pode se dar ao luxo de dizer que não conhece a legislação. A questão é que o pesquisador também não conhece, porque ele não foi informado, ele não foi educado, nós não temos ainda uma cultura da bioética, ela é uma cultura rara" (E7).

Essa falta de conhecimento assinalada por E7 se materializa em outro momento das entrevistas, na fala de E6: "E onde é que eu posso ajudar mais especificamente? Já que eu não conheço esses meandros, nem essa legislação que você citou aí [Resolução CNS 466/2012], por isso que eu pedi a você pra fazer uma sinopse de cada uma" (E6). O desconhecimento de E6 a respeito da legislação brasileira sobre ética em pesquisa com seres humanos pode ser efeito da época em que o entrevistado se formou, quando ainda não estava em vigor a Resolução CNS 196/1996 ${ }^{26}$.

Segundo Fare ${ }^{8}$, estudo sobre o ensino da ética em pesquisa no país - mais especificamente na pós-graduação stricto sensu, na área da saúde, em que o debate sobre o campo é mais intenso surpreende por evidenciar que ainda há pouca preocupação com a formação ética de futuros professores e pesquisadores: apenas $0,78 \%$ dos cursos avaliados apresentam o tema da ética em pesquisa como disciplina autônoma na estrutura curricular.

\section{Considerações finais}

Por meio da análise das práticas discursivas, focalizou-se a perspectiva de professores-pesquisadores que atuam na linha das TDIC sobre ética em pesquisa on-line. A partir do diálogo com os participantes, foi possível produzir sentidos sobre questões éticas tanto de modo geral como especificamente em relação à produção on-line do conhecimento. Ficou clara a relevância do tema, sobretudo no que se refere ao reconhecimento do participante da pesquisa como cidadão de direitos.

$\mathrm{Na}$ fala dos participantes foi possível observar a variedade de sentidos atribuídos à palavra "ética", o que gera diferentes posturas ante determinada situação de pesquisa. De um lado, percebe-se discurso que reconhece a importância da ética a partir de enfoque procedimental, que reproduz o sistema 
de conduta presente em códigos e juramentos do campo da saúde. Sua vigência indica a necessidade de fortalecer a discussão sobre ética em pesquisa desde a graduação a fim de que se propague uma visão de cuidado mais voltada à dignidade humana. De outro lado, verifica-se abordagem mais direcionada ao cuidado em particular, com ênfase na proteção do participante da pesquisa para além da esfera biomédica, visando garantir direitos individuais. Nessa perspectiva, a relação interpessoal e a confiança superam acordos legais.

Observou-se também que a noção de proteção de alguns entrevistados se refere à salvaguarda judicial do pesquisador, embora em boa parte das falas a ênfase maior tenha sido dada ao cuidado com os participantes da pesquisa. Essa preocupação expressa consonância com a Resolução CNS 466/2012 ${ }^{9}$ e 510/2016 ${ }^{10}$.

Mais especificamente com relação às implicações éticas de pesquisas on-line, foi possível discutir aspectos conceituais e práticos inerentes à produção do conhecimento nesse meio. A complexidade do tema ficou clara, principalmente em razão do rápido avanço das tecnologias, que ampliam a comunicação entre atores sociais e aumentam o acesso à informação, exigindo mais cuidado por parte dos pesquisadores.
A identidade do participante de pesquisas on-line foi tema recorrente, tendo em vista que no ciberespaço as pessoas podem disfarçar sua identidade, fornecendo dados irreais ou até mesmo se fazendo passar por outra pessoa. Para enfrentar essa falta de confiabilidade, que representa problema de avaliação ética, professores-pesquisadores entrevistados sugeriram duas estratégias: a busca de outras fontes de informação, para que se possa confrontar os dados, ou elaboração de questões propositivas.

Por fim, outro ponto importante foi o uso de imagens, fotos e vídeos, em que foi possível constatar que os entrevistados reconhecem a necessidade de obter consentimento dos participantes. Quanto a textos e dados disponíveis on-line, pôde-se perceber a mesma preocupação entre os professores-pesquisadores.

Espera-se que os resultados apresentados possam contribuir para o debate sobre a ética em pesquisas on-line, ajudando professores-pesquisadores a lidar com aspectos éticos inerentes à produção do conhecimento por esse meio. Propõe-se, assim, (des)construir discursos em prol de uma prática científica mais ética, direcionada à proteção dos participantes da pesquisa.

\section{Referências}

1. Lévy P. Cibercultura [Internet]. São Paulo: Editora 34; 1999 [acesso 13 ago 2019]. Disponível: https://bit.ly/3jHJKlz

2. Salvador PTCO, Alves KYA, Rodrigues CCFM, Oliveira LV. Estratégias de coleta de dados online nas pesquisas qualitativas da área da saúde: scoping review. Rev Gaúcha Enferm [Internet]. 2020 [acesso 12 jun 2020];41:e20190297. DOI: 10.1590/1983-1447.2020.20190297

3. Spink MJ, Frezza RM. Práticas discursivas e produção de sentidos: a perspectiva da psicologia social. In: Spink MJ, organizadora. Práticas discursivas e produção de sentidos no cotidiano: aproximações teóricas e metodológicas. Rio de Janeiro: Centro Edelstein de Pesquisas Sociais; 2013. p. 1-21. p. 15.

4. Spink MJ, Frezza RM. Op. cit. p. 19.

5. Spink MJ, Frezza RM. Op. cit. p. 20.

6. Aragaki SS, Lima MLC, Pereira CCQ, Nascimento VLV. Entrevistas: negociando sentidos e coproduzindo versões de realidade. In: Spink MJP, Brigagão JIM, Nascimento VLV, Cordeiro MP, organizadoras. A produção de informação na pesquisa social: compartilhando ferramentas [Internet]. Rio de Janeiro: Centro Edelstein de Pesquisas Sociais; 2014 [acesso 13 ago 2019]. p. 57-72. Disponível: https://bit.ly/3bLgVkl

7. Fare M, Machado FV, Carvalho ICM. Breve revisão sobre regulação da ética em pesquisa: subsídios para pensar a pesquisa em educação no Brasil. Práxis Educativa [Internet]. 2014 [acesso 12 fev 2021];9(1):247-83. DOI: 10.5212/PraxEduc.v.9i1.0012

8. Fare M. Ética no processo de formação de pesquisadores. In: Associação Nacional de Pós-Graduação e Pesquisa em Educação. Ética e pesquisa em educação: subsídios. Rio de Janeiro: Anped; 2019. p. 119-23. 
9. Conselho Nacional de Saúde. Resolução CNS n 466, de 12 de dezembro de 2012. Aprova diretrizes e normas regulamentadoras de pesquisas envolvendo seres humanos. Diário Oficial da União [Internet]. Brasília, n 12, p. 59, 13 jun 2013 [acesso 28 fev 2018]. Seção 1. Disponível: https://bit.ly/20ZpTyq

10. Conselho Nacional de Saúde. Resolução CNS n 510 , de 7 de abril de 2016. Dispõe sobre as normas aplicáveis a pesquisas em ciências humanas e sociais cujos procedimentos metodológicos envolvam a utilização de dados diretamente obtidos com os participantes ou de informações identificáveis ou que possam acarretar riscos maiores do que os existentes na vida cotidiana, na forma definida nesta Resolução. Diário Oficial da União [Internet]. Brasília, n 98, p. 44-6, 24 maio 2016 [acesso 12 fev 2021]. Seção 1. Disponível: https://bit.ly/3qeFjkZ

11. Pereira AC, Schmitt V, Dias MRA. Ambientes virtuais de aprendizagem. In: Pereira AC, organizadora. AVA: ambientes virtuais de aprendizagem em diferentes contextos. Rio de Janeiro: Ciência Moderna; 2008. p. 1-22. p. 15.

12. Schmidt MLS. Aspectos éticos nas pesquisas qualitativas. In: Guerriero ICZ, Schmidt MLS, Zicker F, organizadores. Ética nas pesquisas em ciências humanas e sociais na saúde [Internet]. $2^{\mathrm{a}}$ ed. São Paulo: Hucitec; 2011 [acesso 2 dez 2019]. p. 47-54. p. 47. Disponível: https://bit.ly/3jPws6L

13. Guilhem D, Diniz D. O que é bioética. São Paulo: Brasiliense; 2008. p. 61.

14. Engelhardt JHT. After God: morality and bioethics in a secular age. Bioethikos [Internet]. 2014 [acesso 5 mar 2021];8(1):80-8. DOI: 10.15343/1981-8254.20140801080088

15. Dallari GS. A proteção do direito à intimidade, a confidencialidade e o sigilo nas pesquisas em saúde. In: Guerriero ICZ, Schmidt MLS, Zicker F, organizadores. Ética nas pesquisas em ciências humanas e sociais na saúde [Internet]. $2^{a}$ ed. São Paulo: Hucitec; 2011 [acesso 2 dez 2019]. p. 53-82. p. 53. Disponível: https://bit.ly/378QvYD

16. Schmidt MLS. Op. cit.

17. Schmidt MLS. Op. cit. p. 48.

18. Schmidt MLS. Op. cit. p. 51.

19. Dallari GS. Op. cit. p. 80-1.

20. Moore M, Kearsley G. Educação a distância: uma visão integrada. São Paulo: Thomson; 2007. p. 167.

21. Bauman Z. Responsabilidades morais, normas éticas. In: Bauman Z. Ética pós-moderna. São Paulo: Paulus; 1997. p. 23-46.

22. Brasil. Lei ${ }^{\circ} 12.965$, de 23 de abril de 2014. Estabelece princípios, garantias, direitos e deveres para o uso da internet no Brasil. Diário Oficial da União [Internet]. Brasília, p. 1, 24 abr 2014 [acesso 18 ago 2019]. Disponível: https://bit.ly/3d1fqkO

23. Bakardjieva M, Feenberg A. Community technology and democratic rationalization. Inf Soc [Internet]. 2002 [acesso 13 ago 2019];18(3):181-92. DOI: 10.1080/01972240290074940

24. Kozinets RV. Netnografia: realizando pesquisa etnográfica online. Porto Alegre: Penso; 2014.

25. Freitas H, Janissek-Muniz R, Andriotti FK, Freitas P, Costa RS. Pesquisa via internet: características, processo e interface. Rev Eletrônica Gianti [Internet]. 2004 [acesso 12 fev 2021]. Disponível: https://bit.ly/2NmiBZk

26. Conselho Nacional de Saúde. Resolução CNS n 196, de 10 de outubro de 1996. Aprova as diretrizes e normas regulamentadoras de pesquisas envolvendo seres humanos. Diário Oficial da União [Internet]. Brasília, p. 21082, 16 out 1996 [acesso 12 fev 2021]. Seção 1. Disponível: https://bit.ly/3qeFjkZ 
Luiz Wilson Machado da Costa e Silva Neto - Mestre - Iwmachado.neto@gmail.com (iD) $0000-0002-3280-4543$

Deise Juliana Francisco - Doutora - deisej@gmail.com (iD) 0000-0003-2130-2588

\section{Correspondência}

Deise Juliana Francisco - Rua Elias Ramos de Araújo, 264, apt. 301, Cruz das Almas CEP 57038-280. Maceió/AL, Brasil.

\section{Participação dos autores}

Luiz Wilson Machado da Costa e Silva Neto coletou e analisou os dados e redigiu o artigo. Deise Juliana Francisco orientou o trabalho e contribuiu com a redação do texto.

Recebido: 24.5 .2019

Revisado: 29.1 .2021

Aprovado: 5.2 .2021 